\title{
Melatonin may increase disease resistance and flavonoid biosynthesis through effects on DNA methylation and gene expression in grape berries
}

Shiwei Gao, Wanyun Ma, Xinning Lyu, Xiaolei Cao and Yuxin Yao* (D)

\begin{abstract}
Background: Melatonin can regulate plant growth, development and biotic responses by causing global changes in gene expression; however, the melatonin-induced changes in gene expression via the modification of DNA methylation remain unclear in plants.

Results: A total of 1,169,852 and 1,008,894 methylated cytosines (mCs) were identified in the control and melatonin-treated grape berries, respectively, and mCs occurred primarily at CG sites, followed by CHG sites and $\mathrm{CHH}$ sites. Compared to the control, melatonin treatment broadly decreased methylation levels at $\mathrm{CHG}$ and particularly $\mathrm{CHH}$ sites in various gene regions. Melatonin treatment generated a total of 25,125 differentially methylated regions (DMRs), which included 6517 DMR-associated genes. RNA-Seq demonstrated that 2479 genes were upregulated, and 1072 genes were repressed by melatonin treatment. The evaluation of the interconnection of the DNA methylome and transcriptome identified 144 genes showing a negative correlation between promoter methylation and gene expression, which were primarily related to biotic stress responses and flavonoid biosynthesis. Additionally, the application of 5 -azacytidine and melatonin led to similar effects on mycelial growth of B. cinerea, berry decay rate and flavonoid biosynthesis. Moreover, EDS1 was used to show that melatonin increased gene expression by decreasing promoter methylation levels.
\end{abstract}

Conclusion: Our results demonstrated that melatonin broadly decreased DNA methylation and altered gene expression in grape berries. We propose that melatonin increases disease resistance and flavonoid biosynthesis by decreasing the methylation levels of the promoters of the genes involved.

Keywords: Melatonin, Methylome, Transcriptome, Flavonoid biosynthesis, Disease resistance, Grape berries

\section{Background}

Grapevine is one of the most important economic fruit crops worldwide. Strategies for improving quality and disease resistance are a key focus of grapevine cultivation. The whole grape berry, including the skin, pulp

\footnotetext{
* Correspondence: yaoyx@sdau.edu.cn

State Key Laboratory of Crop Biology, Collaborative Innovation Center of Fruit \& Vegetable Quality and Efficient Production, College of Horticulture Science and Engineering, Shandong Agricultural University, Tai-An 271018, Shandong, China
}

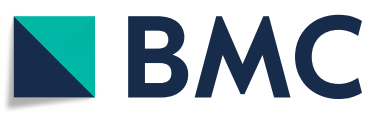

and seeds, contains melatonin ( $\mathrm{N}$-acetyl-5-methoxytryptamine) [1]. Melatonin is a signaling molecule that plays protective roles against biotic and abiotic stresses. Melatonin participates in the regulation of tolerance to various plant diseases. For example, melatonin induces disease resistance to Botrytis cinerea in tomato fruit by regulating JA signaling and $\mathrm{H}_{2} \mathrm{O}_{2}$ levels and improves the disease resistance of Arabidopsis against pathogen infection via $\mathrm{NO}$ signaling $[2,3]$. The increase in

(c) The Author(s). 2020 Open Access This article is licensed under a Creative Commons Attribution 4.0 International License, which permits use, sharing, adaptation, distribution and reproduction in any medium or format, as long as you give appropriate credit to the original author(s) and the source, provide a link to the Creative Commons licence, and indicate if changes were made. The images or other third party material in this article are included in the article's Creative Commons licence, unless indicated otherwise in a credit line to the material. If material is not included in the article's Creative Commons licence and your intended use is not permitted by statutory regulation or exceeds the permitted use, you will need to obtain permission directly from the copyright holder. To view a copy of this licence, visit http://creativecommons.org/licenses/by/4.0/ The Creative Commons Public Domain Dedication waiver (http://creativecommons.org/publicdomain/zero/1.0/) applies to the data made available in this article, unless otherwise stated in a credit line to the data. 
melatonin content activated by MeRAV1 and MERAV2 enhances plant disease resistance against cassava bacterial blight [4]. Additionally, both exogenous treatment with and endogenous induction of melatonin increase abiotic stress tolerance in many plants. It has been reported that melatonin alleviates salt damage in grapes [5] and enhances the drought tolerance of apple plants [6]. Endogenously increasing melatonin via the overexpression of ASMT1 significantly enhances the drought tolerance of Arabidopsis plants [7].

Melatonin is a multifunctional signaling molecule [8] that promotes grape berry ripening and quality formation via its interplay with other signaling molecules [9]. Melatonin has also been reported to promote tomato and banana ripening and thereby affect fruit quality $[10$, 11]. Additionally, some other studies have emphasized the role of melatonin in regulating metabolite accumulation in fruits. For example, melatonin treatment enhances the contents of total anthocyanins, phenols and flavonoids in grape berries and wine [12, 13]. Postharvest treatment with melatonin increases the contents of total phenols and anthocyanins in tomato fruits [10].

The effects of melatonin on stress tolerance and fruit development are largely ascribed to the regulation of gene expression. Global gene expression changes caused by melatonin revealed that melatonin induces salt tolerance via ROS scavenging in rice shoots [14]. Transcriptomic analysis revealed global changes in gene expression related to polyphenol metabolism, carbohydrate metabolism and ethylene biosynthesis and signaling upon melatonin treatment in grape berries [12]. Proteomics data show that 241 proteins are significantly influenced by melatonin in tomato fruits [15]. Arnao and Hernández-Ruiz summarized the genes that are upand downregulated by melatonin under given physiological conditions, including various abiotic stressors and biotic stressors in different plants [16].

DNA methylation is an important epigenetic modification that plays a very important role in the regulation of multiple biological processes, including stress responses, growth, development and fruit ripening, by modulating gene expression pretranscriptionally $[17,18]$. Methylome analysis showed that most DNA methylation-modified genes are transcriptionally altered under $\mathrm{Cd}$ stress in rice [19], and a global increase in DNA methylation occurs during orange fruit ripening [20]. Additionally, some specific genes, such as fruit ripening-related RIN and PSY1, show demethylation at their promoters to activate their transcription during fruit ripening [21]. Notably, an increasing number of studies indicate that melatonin alters global DNA methylation levels [22] or the DNA methylation of specific genes [23] in humans. However, the regulation of gene expression by melatonin via the modification of methylation remains unclear in plants.
In this study, the DNA methylome and RNA transcriptome were analyzed in control and melatonin-treated grape berries, and the analysis of their interconnection revealed the key role of melatonin in increasing flavonoid biosynthesis and disease resistance. These functions of melatonin were further verified by determining the melatonin-induced changes in flavonoid contents, the berry decay rate and the levels of expression and promoter methylation of selected genes. These findings provide a new perspective for understanding the role of melatonin in regulating gene transcription in grape berries.

\section{Results}

Exogenous melatonin treatment increases melatonin content in 'merlot' grape berries

Exogenous melatonin treatment was used to increase the melatonin content of grape berries. Veraison (onset of berry ripening) is the key period for ripening regulation using signaling molecules, and melatonin levels begin to increase at veraison [9]. The occurrence of veraison was indicated by the accumulation of sugars and anthocyanins and a decline in titratable acidity. In the 'Merlot' grape berries, anthocyanins began to accumulate at 80 days after bloom (DAB), and coloring began at 90 DAB (Fig. 1a, b). Total soluble solids (TSS) and titratable acid continued to accumulate and decrease, respectively, from 80 DAB onward (Fig. 1a, b). Therefore, veraison occurred at approximately $80 \mathrm{DAB}$, and melatonin treatment was performed at this time point. Treatment with $50 \mu \mathrm{M}$ melatonin significantly increased the melatonin content of the berries, and increments of 1.24-, 4.45and 9.02-fold were generated at 4, 48 and $144 \mathrm{~h}$ after treatment (HAT), respectively, compared with the control berries (Fig. 1c).

\section{DNA methylation profiling in control and melatonin- treated 'merlot' grape berries}

Control and melatonin-treated berries collected at 48 HAT were used for single-base DNA methylation BSSeq. A total of $877,654,62$ and $889,758,30$ clean reads were generated, with high conversion rates ( $C$ to $G$ ) of 99.54 and $99.47 \%$, respectively. The average read depth of the control and melatonin-treated berries was $12.25 \mathrm{G}$ and $12.42 \mathrm{G}$, respectively, accompanied by mapping rates of 54.33 and $54.31 \%$ (Table S1). A total of 1,169,852 and $1,008,894$ methylated cytosines $(\mathrm{mCs})$ were identified in the control and melatonin-treated grapes, respectively. In the control/melatonin treatments, $42.10 \% / 40.52 \%$ mCs were identified at CG sites, $30.35 \% / 29.47 \%$ at CHG sites and $27.53 \% / 29.99 \%$ at $\mathrm{CHH}$ sites $(\mathrm{H}=\mathrm{A}, \mathrm{T}$, or $\mathrm{C})$ (Table S1).

The control and melatonin-treated berries showed very similar $\mathrm{mC}$ profiles on 19 chromosomes (Fig. 2a). 


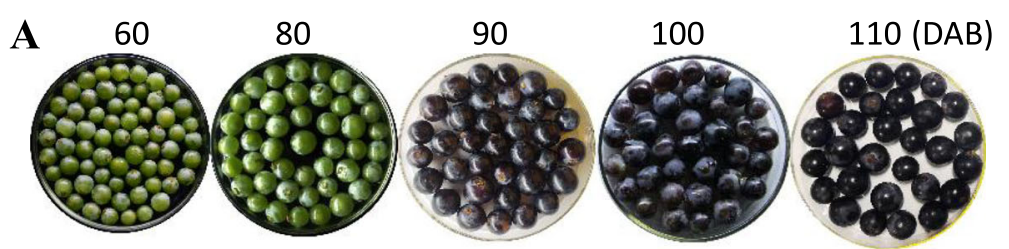

B

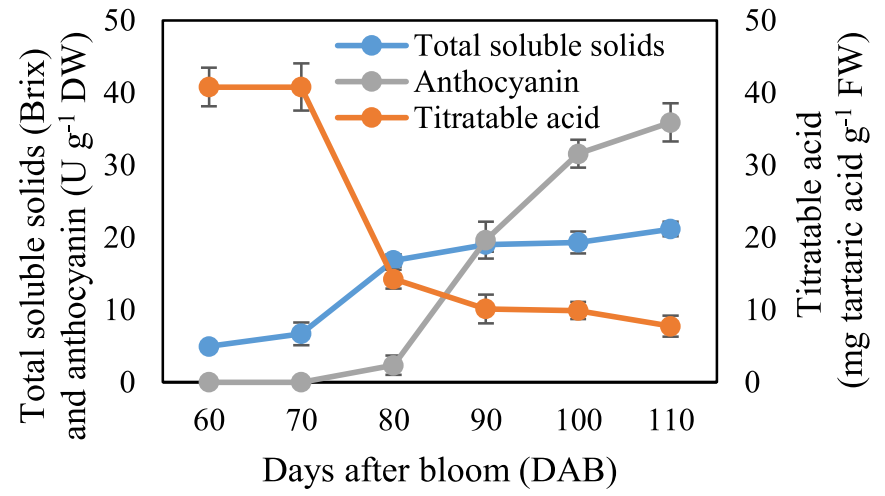

C

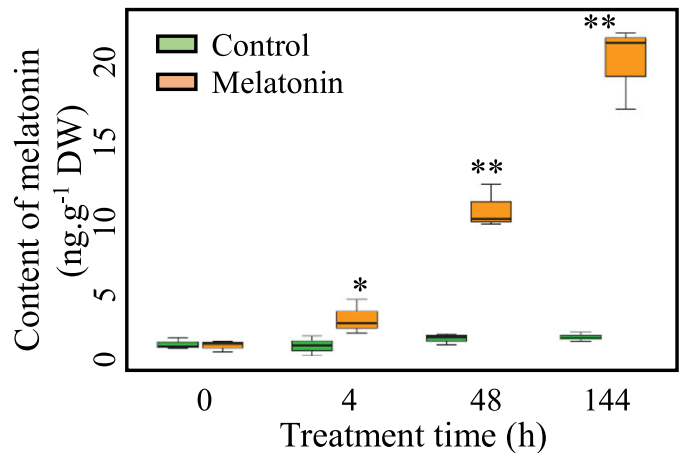

Fig. 1 Determination of berry veraison $(\mathbf{a}, \mathbf{b})$ and changes in melatonin content $(\mathbf{c})$ in 'Merlot' berries under $50 \mu \mathrm{M}$ melatonin treatment. Berry veraison was indicated by berry coloring, increases in total soluble solids and anthocyanins and decreases in titratable acid. Values represent the means \pm SD of three replicates. * Significant difference, $P<0.05$; ${ }^{*}$ highly significant difference, $P<0.01$

The three types of mCs exhibited similar distribution patterns on the same chromosome. In contrast, the different chromosomes showed varying methylation levels and $\mathrm{mC}$ distributions. For example, Chrs 16 and 8 possessed the highest and lowest levels of methylation, respectively, among the chromosomes; a high- $\mathrm{mC}$ region occurred around the central position of Chrs 4, 6, and 7, while high methylation levels were found on one side of Chrs 18, 1, 8 and 17 (Fig. 2a). Additionally, a high methylation level was detected in the CG context compared to the $\mathrm{CHG}$ and $\mathrm{CHH}$ contexts in the control and melatonin-treated berries (Fig. 2b). The comparison of methylation levels between the control and melatonintreated berries revealed that a higher percentage of differentially methylated cytosines in exons than in promoters, introns and downstream regions (Fig. 2c). Additionally, the gene body generally showed a much higher methylation level than its upstream and downstream regions (Fig. 2b). Moreover, melatonin greatly reduced methylation levels in $\mathrm{CHH}$ contexts in the upstream, gene body and downstream regions of genes. In contrast, melatonin widely decreased methylation levels in $\mathrm{CHG}$ contexts to a lesser extent in various gene regions and led to a slight decline in CG methylation levels only in gene bodies (Fig. 3b).

\section{Gene ontology (GO) and KEGG enrichment of differentially methylated region (DMR)-related genes}

A total of 25,125 DMRs were detected (fold change $\geq 4$ or $\leq 0.25, P<0.05)$ between the control and melatonintreated berries. Compared to the control, the methylation levels of 9000 and 16,125 DMRs were increased and decreased, respectively, by melatonin in grape berries. The total DMRs included 6517 DMR-associated genes in upstream, exon, intron and downstream regions (Table S2).

GO enrichment of the DMR-associated genes showed that the three most significantly altered biological processes were dTDP-rhamnose biosynthetic processes, 

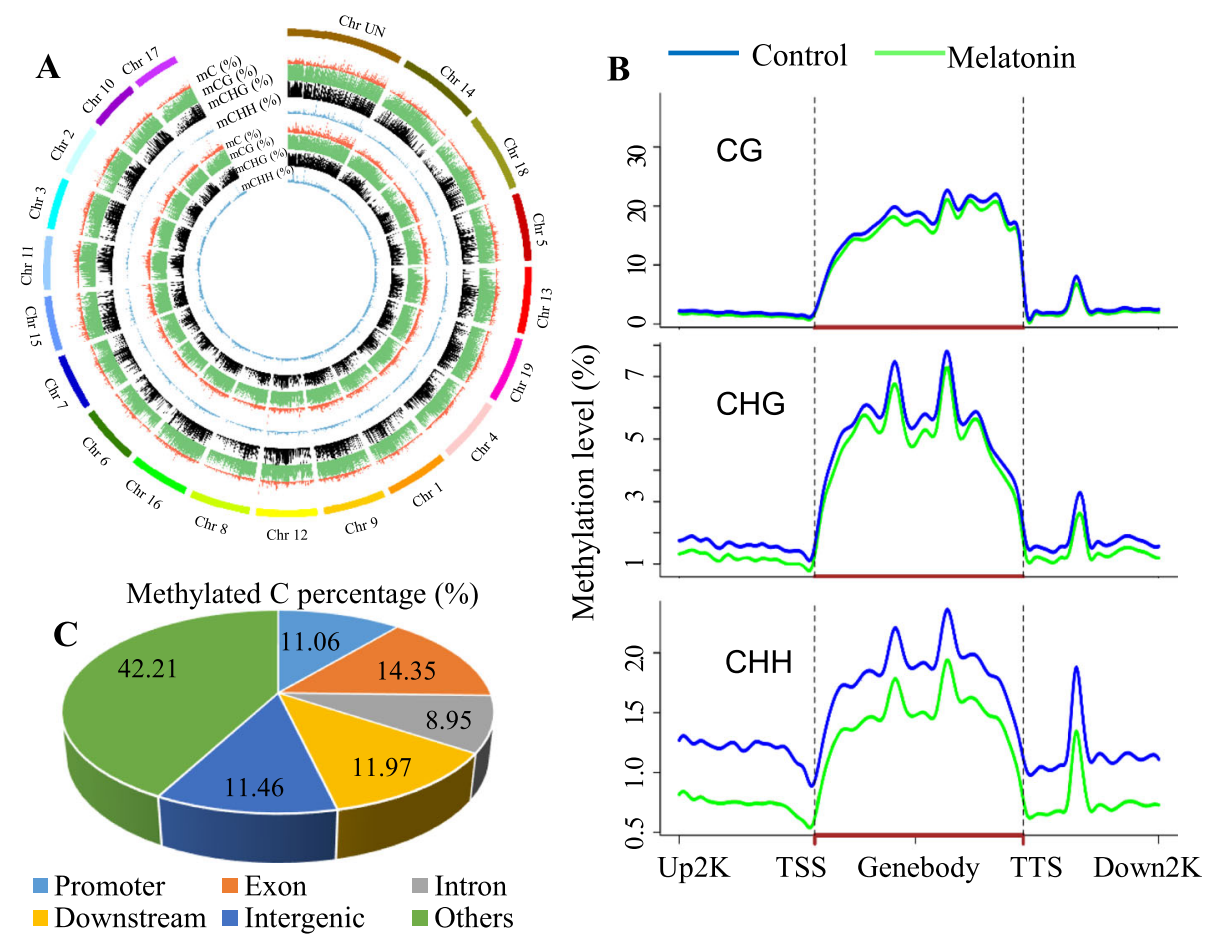

Fig. 2 Methylation levels of different chromosomes and genomic regions in 'Merlot' berries. a The outermost bold lines indicate different chromosomes and their lengths at a 50 kilobase resolution. Red, green, black and blue peak shape diagrams indicate the methylation levels of $\mathrm{mC}, \mathrm{mCG}, \mathrm{mCHG}$ and $\mathrm{mCHH}$, respectively, at different chromosome sites, and the peak height indicates the methylation level. The second to fifth circles are from control berries, and the sixth to ninth circles are from melatonin-treated berries. $\mathbf{b}$ Changes in the levels of CG, CHG and CHH methylation in melatonin-treated berries compared to the control. TSS, transcription start site. TTS, transcription termination site. Up2K and Down2K represent the $2000 \mathrm{bp}$ upstream of the $\Pi \mathrm{S}$ and downstream of the $T \mathrm{~S}$, respectively. $\mathbf{c}$ Percentages of differentially methylated cytosines in different genomic regions

ethanol metabolic processes and iron chelate transport. Enzyme-directed rRNA 2'-O-methylation and alternative mRNA splicing via the spliceosome were also significantly changed (Fig. 3a). The molecular functions of the DMR-associated genes primarily included carbohydrate kinase activity, cholesterol binding, triosephosphate transmembrane transporter activity and cystathionine gamma-lyase activity. Most of the DMRassociated proteins were located in the nucleus (Fig. 3a). KEGG pathway analysis indicated that the three most significantly changed pathways were pentose and glucoronate interconversion, inositol phosphate metabolism, and fatty acid degradation. Additionally, the metabolism of amino acids, including lysine, linoleic acid and alphalinolenic acid, and phenolics, including carotenoids and isoflavonoids, was significantly altered (Fig. 3b).

\section{Melatonin treatment alters global gene expression patterns in 'merlot' grape berries}

RNA-Seq was employed to detect the transcript abundance of the control and melatonin-treated berries. A total of 3551 differentially expressed genes (DEGs) $\left(\left|\log _{2} \mathrm{FC}\right|>1, \quad P<0.05\right)$ were identified in melatonin- treated berries compared to the control. Compared to the control, 2479 genes were upregulated, and 1072 genes were repressed (Table S3, Fig. 4a). GO enrichment demonstrated that the DEGs in the biological process category were primarily related to defense responses, including the responses to biotic stimuli, chitin and fungi. Among molecular functions, the DEGs were mainly involved in trihydroxystilbene synthase activity, DNA binding transcription factor activity and isomerase activity. The inferred proteins of the DEGs were primarily located in the apoplast and plasma membrane (Fig. 4b). KEGG pathway analysis showed that the most significantly altered pathways were flavonoid biosynthesis, circadian rhythm-plant and plant-pathogen interaction pathways (Fig. 4c).

\section{Interconnection of the DNA methylome and RNA transcriptome}

A total of 1626 genes were identified via a cross-analysis of DMR-related genes and DEGs. Among these genes, the expression levels of 886 genes $(54.5 \%)$ were negatively related to their methylation levels, and 740 genes (45.5\%) showed a positive relationship between 

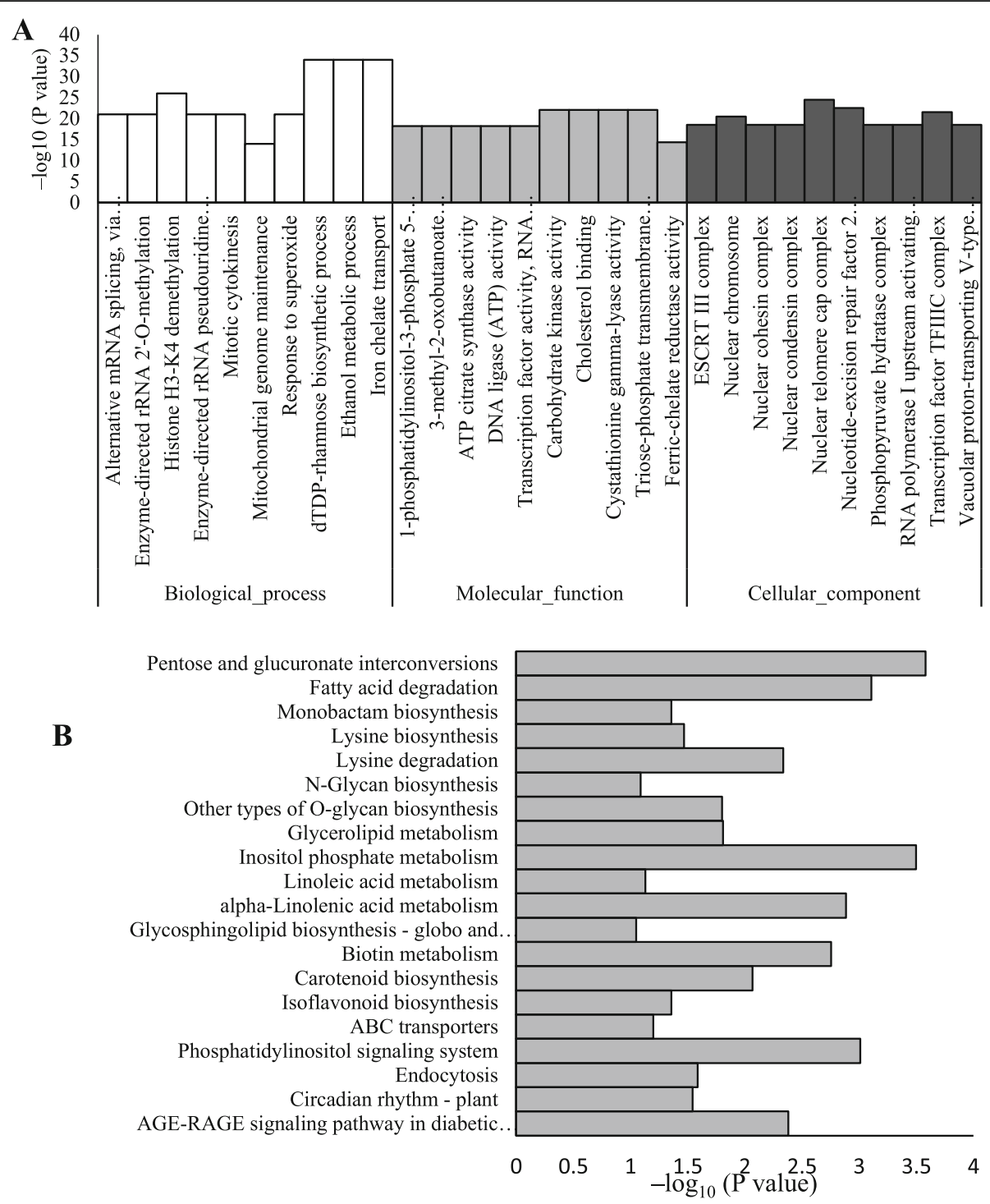

Fig. 3 Analysis of the GO (a) and KEGG enrichment (b) of DMR-associated genes. $P$ values are corrected to $-\log _{10}(P$ values) ranging from 0 to infinity, and a lower $P$ value (i.e., a greater $-\log _{10}(P$ value)) indicates a higher intensity. The top $10 \mathrm{GO}$ enrichments and the top 20 enriched KEGG pathways are displayed in this paper

expression and methylation levels (Table S4, Fig. 5a). Additionally, most of the interconnected genes showed upregulated expression levels in melatonin-treated berries compared to the control (Fig. 5a).

It is well established that methylation at a gene promoter region can inhibit DNA transcription [24]. In this study, we identified 144 differentially methylated promoter (DMP)-related genes exhibiting a negative association between promoter methylation levels and expression levels, among which 133 genes presented upregulated expression and decreased promoter methylation, and 13 genes showed the opposite relationship (Table S5). To verify the association between the levels of promoter methylation and gene expression, three genes involved in flavonoid biosynthesis and plantpathogen interaction (Table 1) were selected for analysis by methylation-specific PCR (MS-PCR) and qRT-PCR. Compared to the control, the melatonin-treated berries exhibited a low level of promoter methylation and a high level of gene expression (Fig. 5b, c). Almost all of the interconnected genes were related to defense responses, including responses to biotic stimuli, salicylic acid, chitin, bacteria and fungi. Their molecular functions included ferric-chelate reductase, calcium-transporting ATPase, and trihydroxystilbene synthase enzyme activities. The inferred proteins were located in the plasma membrane and outside the plasma membrane (Fig. 5d). Additionally, two KEGG pathways were significantly 

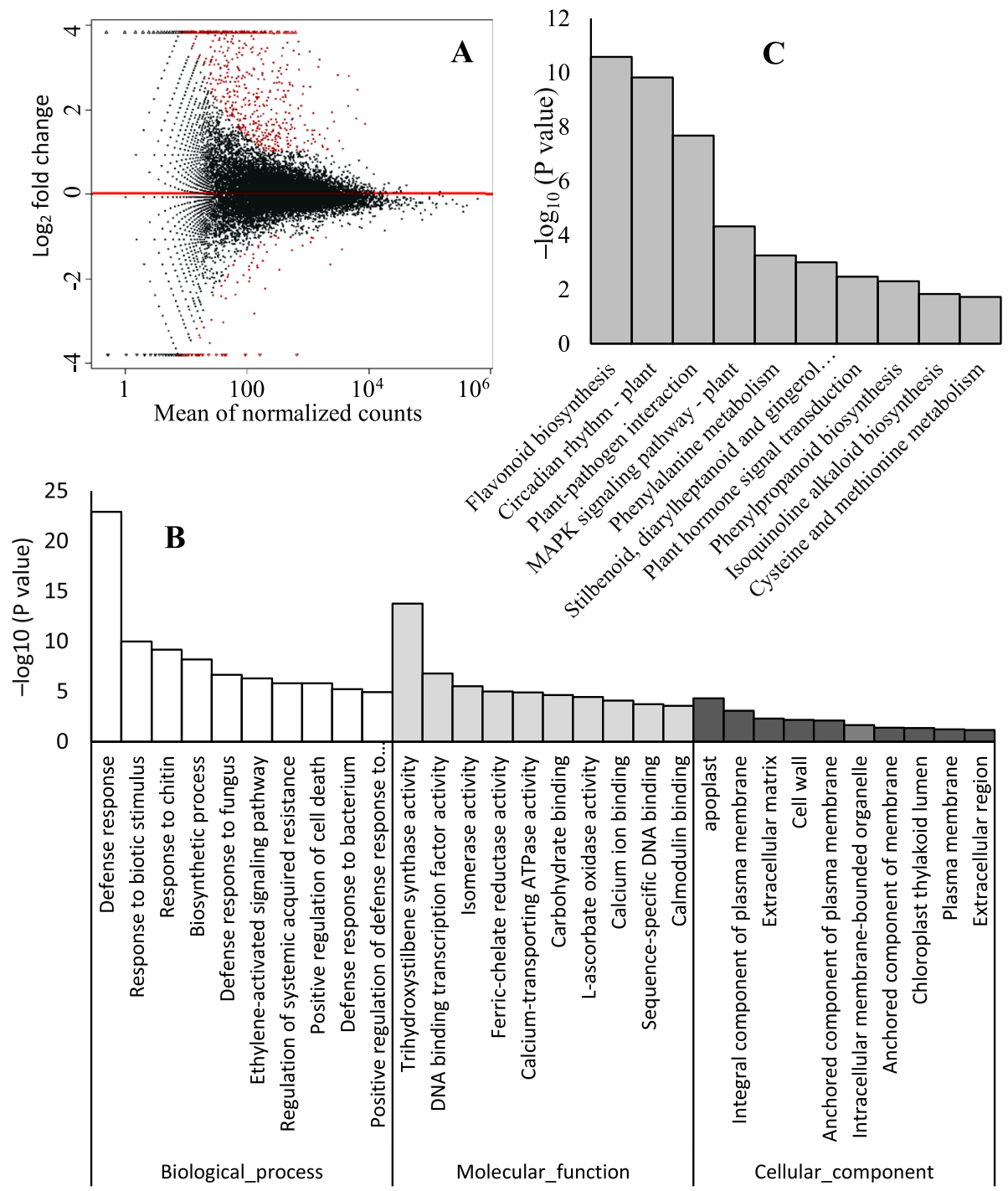

Fig. 4 Analysis of GO and KEGG enrichment of differentially expressed genes (DEGs) between the control and melatonin-treated 'Merlot' berries. a Differential transcript abundance between control and melatonin-treated berries. Red dots indicate differentially expressed genes. $\mathbf{b} \mathrm{GO}$ clustering analysis of DEGs based on their functional enrichment. The top $10 \mathrm{GO}$ enrichments are displayed. c KEGG enrichment analysis of DEGs. The top 10 enriched pathways are displayed. $P$ values are corrected to $-\log _{10}(P$ values) ranging from 0 to infinity, and a lower $P$ value (i.e., greater $-\log _{10}(P$ value $\left.)\right)$ indicates a higher intensity

altered based on these 144 genes: plant-pathogen interaction $\left(P=7.57 \times 10^{-6}\right)$ and flavonoid biosynthesis $(P=$ $\left.7.47 \times 10^{-4}\right)$.

In addition, the gene functions of the 17 genes with the largest changes in expression $\left(\left|\log _{2} \mathrm{FC}\right|>3\right.$ or detected only in melatonin-treated berries) and methylation levels $\left(\left|\log _{2} \mathrm{FC}\right|>2\right.$ or detected only in control berries) in the promoter region are listed. Among these genes, PAL1 and STS1 are responsible for flavonoid biosynthesis. The functions of four of the genes are unknown. The remaining genes including EDS1 and CML41 are involved in disease resistance and/or abiotic stress responses (Table 1).

\section{Melatonin and DNA methylation inhibitor treatments} increase disease resistance and flavonoid accumulation in grape berries

To investigate whether melatonin affected the disease resistance of grape berries, $50 \mu \mathrm{M}$ melatonin treatment of detached 'Merlot' and 'Shine Muscat' berries was performed. Melatonin clearly decreased mycelial growth on the surface of wounded 'Merlot' berries inoculated with Botrytis cinerea (B. cinerea) compared with the control berries (Fig. 6a). Melatonin decreased the decay rate of 'Shine Muscat' berries without inoculation with $B$. cinerea at 14 and 21 DAT (Fig. 6b, c). Additionally, the commonly used DNA methylation inhibitor 5- 

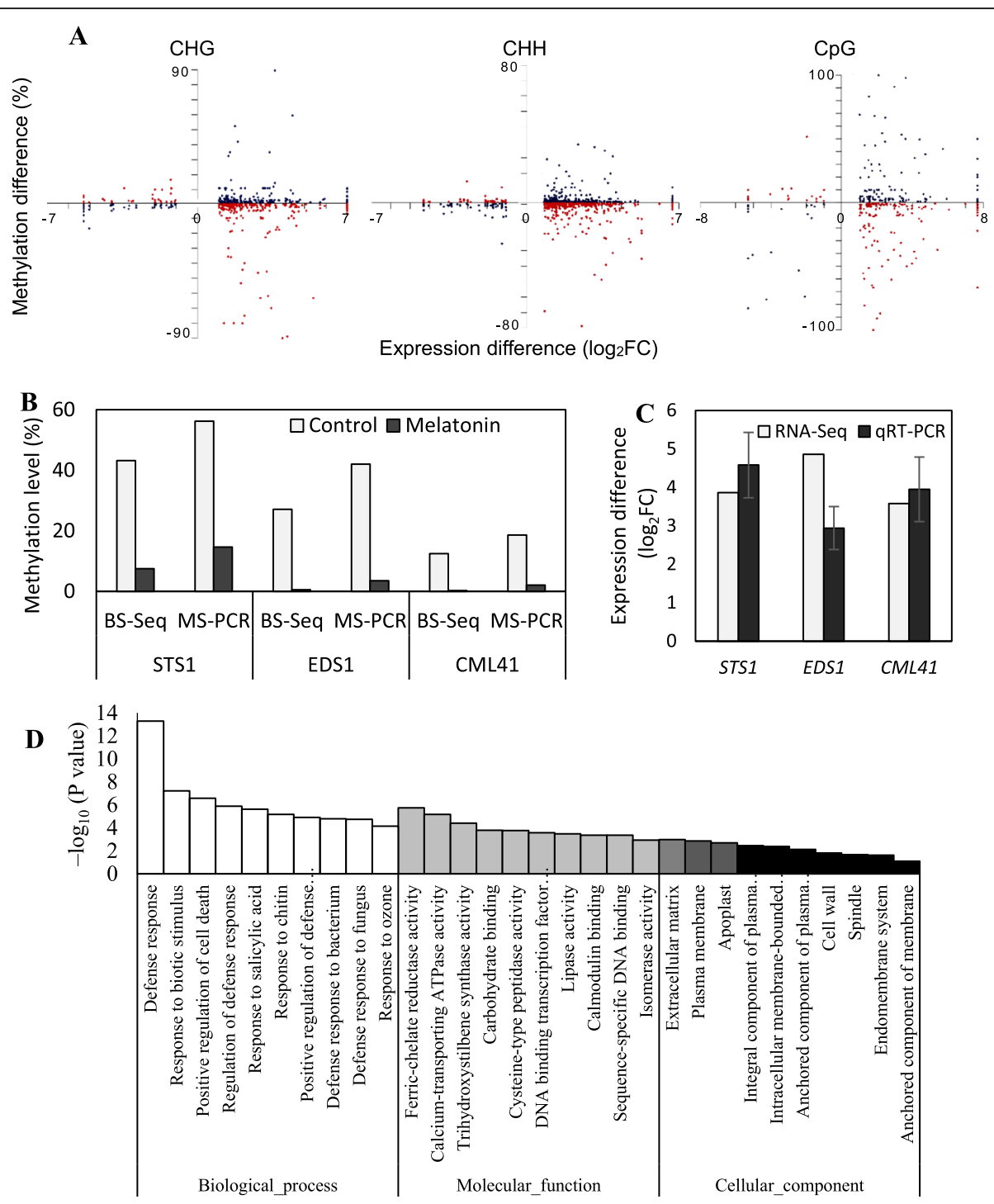

Fig. 5 Cross-sectional analysis of differentially methylated genes and DEGs and GO enrichment of the interconnected genes. a Cross-analysis was performed between the DMR-related genes and DEGs. Red dots represent negatively related genes, and blue dots represent positively related genes. The $y$-axis represents the differences in methylation levels (\%). The $x$-axis represents the differences in gene expression. $F C$, fold change. $\mathbf{b}$, c Validation of the results obtained from BS-Seq and RNA-Seq via methylation-specific PCR and qRT-PCR analyses of three selected loci. STS1, VIT_216s0100g01100; EDS1, VIT_217s0000g07370; CML41, VIT_218s0001g11830. Functional annotations of the above genes were listed in Table 1. FC (fold change) was calculated using the ratio of the expression in the treated berries to that in the control. $\mathbf{d} \mathrm{GO}$ enrichment of the interconnected genes obtained through the comparison of DMP-related genes and DEGs. The top 10 enriched GO categories are displayed. $P$ values are corrected to $-\log _{10}\left(P\right.$ values) ranging from 0 to infinity, and a lower $P$ value (i.e., greater $-\log _{10}(P$ value)) indicates a higher intensity

azacytidine (5-Aza) was applied in this study [19]. The application of 5-Aza led to similar effects on mycelial growth of $B$. cinerea and berry decay rate compared with melatonin (Fig. 6a-c). Therefore, melatonin and 5-Aza increased disease resistance of grape berries. On the other hand, the effects of melatonin and 5-Aza on the flavonoid content were determined. Melatonin and 5Aza increased the flavonoid content of the 'Merlot' and/ or detached 'Shine Muscat' berries at 3 DAT (Fig. 6d).

Additionally, melatonin upregulated the expression levels of PAL1, STS1, EDS1 and CML41, which are related to flavonoid biosynthesis or plant-pathogen interaction (Table 1), in the 'Merlot' berries at 3 DAT (Fig. 6e). Both melatonin and 5-Aza increased the expression levels of the above four genes in the detached 'Shine Muscat' berries at 3 DAT (Fig. 6f). Moreover, both melatonin and 5Aza decreased the methylation levels in the promoter regions of STS1, EDS1 and CML41 (Fig. 6g). Collectively, melatonin and 5-Aza increased disease resistance and flavonoid accumulation of grape berries, which might be involved in the upregulation of gene expression caused by the demethylation of the promoter regions. 
Table 1 The most significantly altered genes in promoter methylation levels ( $\left|\log _{2} \mathrm{FC}\right|>2$ or detected only in control berries) and expression levels ( $\log _{2} \mathrm{FC} \mid>3$ or detected only in melatonin-treated berries)

\begin{tabular}{|c|c|c|c|c|c|}
\hline \multirow[t]{2}{*}{ Gene accession no } & \multirow{2}{*}{$\begin{array}{l}\text { Position of DNA } \\
\text { methylation }\end{array}$} & \multicolumn{2}{|l|}{$\underline{\left(\log _{2} F C\right)}$} & \multirow[t]{2}{*}{ Gene description } & \multirow[t]{2}{*}{ Gene function } \\
\hline & & Methylation & Expression & & \\
\hline VIT_216s0039g01320 & $\begin{array}{l}\text { chr16: } \\
\text { 724,559-726,558 }\end{array}$ & -2.06 & DT & Phenylalanine ammonia lyase 1 (PAL1) & Flavonoid biosynthesis \\
\hline VIT_216s0100g01100 & $\begin{array}{l}\text { chr16: } \\
16,557,734-16,559 \\
733\end{array}$ & -2.56 & 3.86 & Stilbene synthase 1 (STS1) & \\
\hline VIT_200s0203g00220 & $\begin{array}{l}\text { chrUn: } \\
12,072,634-12,074 \\
633\end{array}$ & DC & DT & $\begin{array}{l}\text { G-type lectin s-receptor-like serine } \\
\text { threonine-protein kinase }\end{array}$ & Immune response ${ }^{30}$ \\
\hline VIT_212s0059g00160 & $\begin{array}{l}\text { chr12: } \\
5,071,913-5,073, \\
912\end{array}$ & -6.64 & DT & Ankyrin repeat-containing protein (ACD6) & $\begin{array}{l}\text { Disease resistance and } \\
\text { antioxidation metabolism }\end{array}$ \\
\hline VIT_217s0000g07370 & $\begin{array}{l}\text { chr17: } \\
8,237,664-8,239 \\
663\end{array}$ & -5.64 & 4.86 & Enhanced disease susceptibility 1 (EDS1) & Plant-pathogen interaction ${ }^{42,43}$ \\
\hline VIT_218s0001g11830 & $\begin{array}{l}\text { chr18: } \\
\text { 10,101,409-10,103, } \\
408\end{array}$ & -5.64 & 3.58 & probable calcium-binding protein CML41 & \\
\hline VIT_204s0008g07140 & $\begin{array}{l}\text { chr4: } \\
7,279,720-7,281 \\
719\end{array}$ & DC & 3.64 & Aspartic proteinase CDR1-like & Disease Resistance ${ }^{36}$ \\
\hline VIT_216s0050g01150 & $\begin{array}{l}\text { chr16: 18052767- } \\
\text { 18,054,766 }\end{array}$ & DC & 4.11 & Heat shock protein 83-like & \\
\hline VIT_204s0044g01420 & $\begin{array}{l}\text { chr4: } \\
22,951,153-22,953 \\
152\end{array}$ & -3.83 & 4.70 & Probable polygalacturonase-like & \\
\hline VIT_210s0003g05450 & $\begin{array}{l}\text { chr10: } 10098885- \\
10,100,884\end{array}$ & -4.32 & 3.41 & Reticuline oxidase-like protein & $\begin{array}{l}\text { Response of plants to pathogenic } \\
\text { attack }\end{array}$ \\
\hline VIT_219s0014g00470 & $\begin{array}{l}\text { chr19: 478152-480, } \\
151\end{array}$ & -3.06 & 3.07 & $\begin{array}{l}\text { Leucine-rich repeat receptor-like serine/ } \\
\text { threonine-protein kinase }\end{array}$ & ${ }_{38}^{\text {MAMP-triggered innate immunity }}$ \\
\hline VIT_210s0003g01220 & $\begin{array}{l}\text { chr10: } \\
2,552,768-2,554 \\
767\end{array}$ & -4.32 & 4.42 & $\begin{array}{l}\text { Heavy metal-associated isoprenylated plant } \\
\text { protein } 26\end{array}$ & $\begin{array}{l}\text { Plant responses to environmental } \\
\text { changes }^{35}\end{array}$ \\
\hline VIT_205s0077g01540 & $\begin{array}{l}\text { chr5: } 1240180-1 \\
242,179\end{array}$ & -2.25 & 3.44 & Pathogenesis-related protein 10 & $\begin{array}{l}\text { Response to biotic and abiotic } \\
\text { stresses }^{37}\end{array}$ \\
\hline VIT_204s0008g03530 & $\begin{array}{l}\text { chr4: } 2888437-2, \\
890,436\end{array}$ & DC & 3.69 & Ankyrin repeat-containing protein & Unknown \\
\hline VIT_203s0063g00550 & $\begin{array}{l}\text { chr3: } \\
\text { 4,059,484-4,061, } \\
483\end{array}$ & DC & 6.01 & Unnamed protein product & Unknown \\
\hline VIT_218s0001g08500 & $\begin{array}{l}\text { chr18: } \\
6,946,257-6,948, \\
256\end{array}$ & -2.40 & 3.51 & Unnamed protein product & Unknown \\
\hline VIT_200s0270g00120 & $\begin{array}{l}\text { chrUn: } \\
19,991,241-19,993 \\
240\end{array}$ & -4.32 & 4.59 & Kunitz-type trypsin inhibitor & Unknown \\
\hline
\end{tabular}

$D C$ detected only in control berries, $D T$ detected only in melatonin-treated berries, $F C$ fold change

The melatonin-induced increase in the promoter transcription-driving capacity is negatively regulated by DNA (cytosine-5)-methyltransferase 1 (MET1)

As shown in Figs. 5b, c and 6e-g, melatonin treatment decreased the promoter methylation levels and increased the expression levels of the three selected genes. Additionally, the expression levels of MET1, MET1B and $S$ - adenosylmethionine-dependent methyltransferase (Sad$M E T)$ were significantly downregulated by melatonin according to the results of RNA-Seq and qRT-PCRs (Fig. 7a), which was consistent with the melatonininduced decrease of methylation levels (Fig. 2b). In contrast, the changes in the expression levels of two CMT2 genes were not associated with the decrease of 

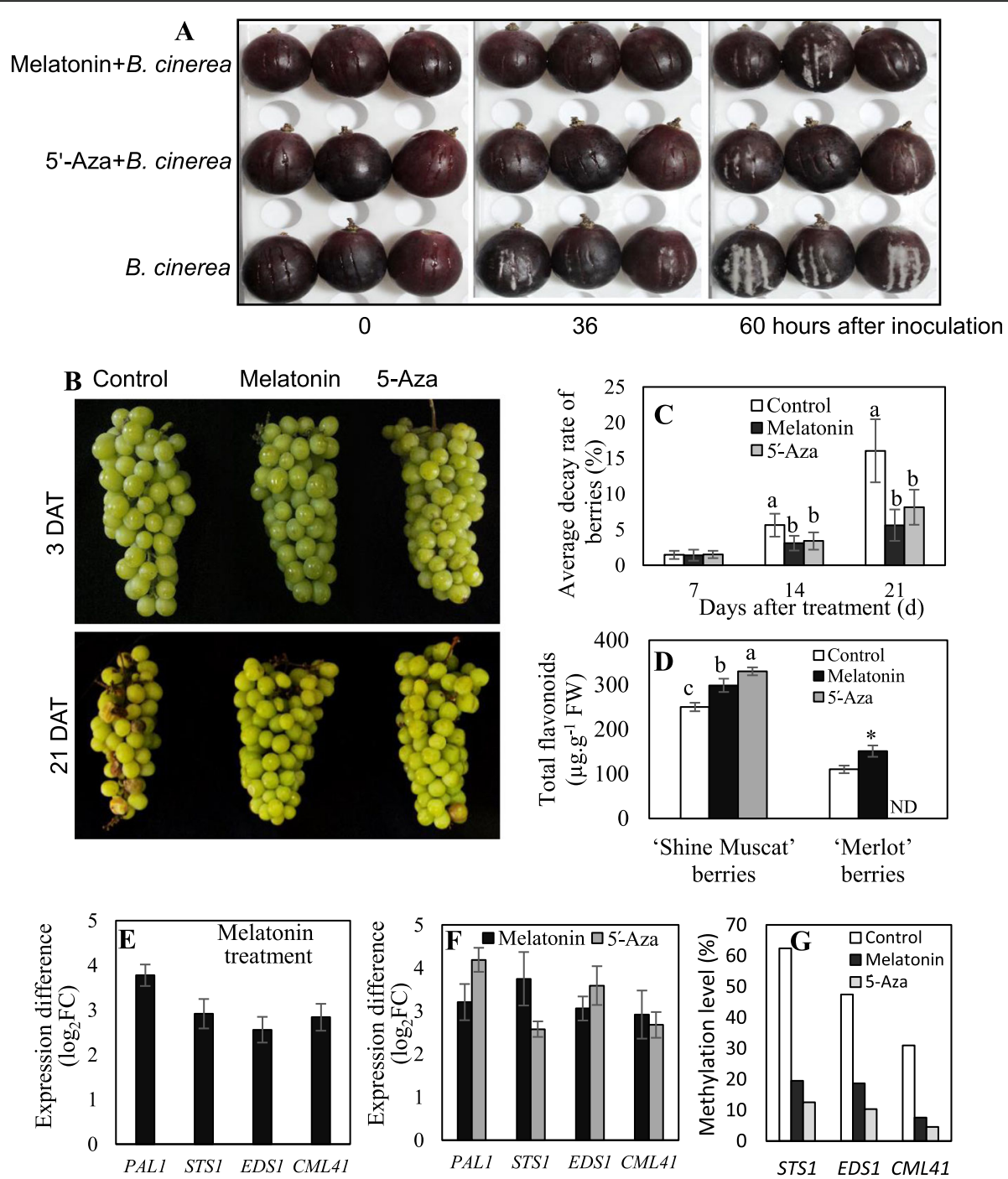

Fig. 6 Effects of melatonin and 5-Aza on disease resistance, flavonoid accumulation, transcripts and DNA methylation of the genes involved in 'Merlot' and/or 'Shine Muscat' berries. a Mycelial growth on B. cinerea-inoculated 'Merlot' berries treated with or without melatonin and 5-Aza. $\mathbf{b}$ Phenotypes of the control and treated 'Shine Muscat' berries with melatonin and 5-Aza. Decayed berries were removed at 21 DAT. c The average decay rate of 'Shine Muscat' berries determined at 21 DAT. $\mathbf{d}$ Flavonoid content in 'Merlot' and detached 'Shine Muscat' berries at 3 DAT. ND, not detected. e, $\mathbf{f}$ Expression difference in 'Merlot' (e) and detached 'Shine Muscat' berries (f) at 3 DAT. FC (fold change) was calculated using the ratio of the expression in the treated berries to that in the control. PAL1, VIT_216s0039g01320; STS1, VIT_216s0100g01100; EDS1, VIT_217s0000g07370; CML41, VIT_218s0001911830. Functional annotations of the above genes were listed in Table 1. g DNA methylation in 'Shine Muscat' berries at 3 DAT

methylation levels under melatonin treatment (Figs. 2b, 7a). To further elucidate whether melatonin regulated gene expression by modifying promoter methylation, MET1 (VIT_212s0035g01770) was used to increase the methylation level of the enhanced disease susceptibility 1 (EDS1) (VIT_217s0000g07370) promoter under melatonin treatment. The Agrobacterium-mediated transient expression of $\mathrm{P}_{\text {eds }}$ (800 bp upstream of ATG of EDS1, Fig. 7a)-35S miniGUS activated GUS expression in grape calluses (Fig. 7c). In contrast to the transformation of $\mathrm{P}_{\text {eds }}-35 \mathrm{~S}$ miniGUS alone, the cotransformation of $\mathrm{P}_{\text {eds }}{ }^{-}$ 35S miniGUS and 35S::MET1 decreased the extent of
GUS staining and GUS activity (Fig. 7c, d). Therefore, the increased methylation level caused by MET1 reduced the transcription-driving capacity of $\mathrm{P}_{\text {eds }}$. Additionally, the melatonin-treated calluses expressing $\mathrm{P}_{\text {eds }}-35 \mathrm{~S}$ miniGUS were bluer in color and showed higher GUS activity than control calluses and melatonin-treated calluses cotransformed with $\mathrm{P}_{\text {eds }}-35 \mathrm{~S}$ miniGUS and 35S::MET1 (Fig. 7c, d). Moreover, the above cotransformants showed an increased methylation level of the EDS1 promoter compared to the calluses expressing $\mathrm{P}_{\text {eds }}-35 \mathrm{~S}$ miniGUS alone under melatonin treatment (Fig. 7e). Collectively, melatonin increased the transcription- 

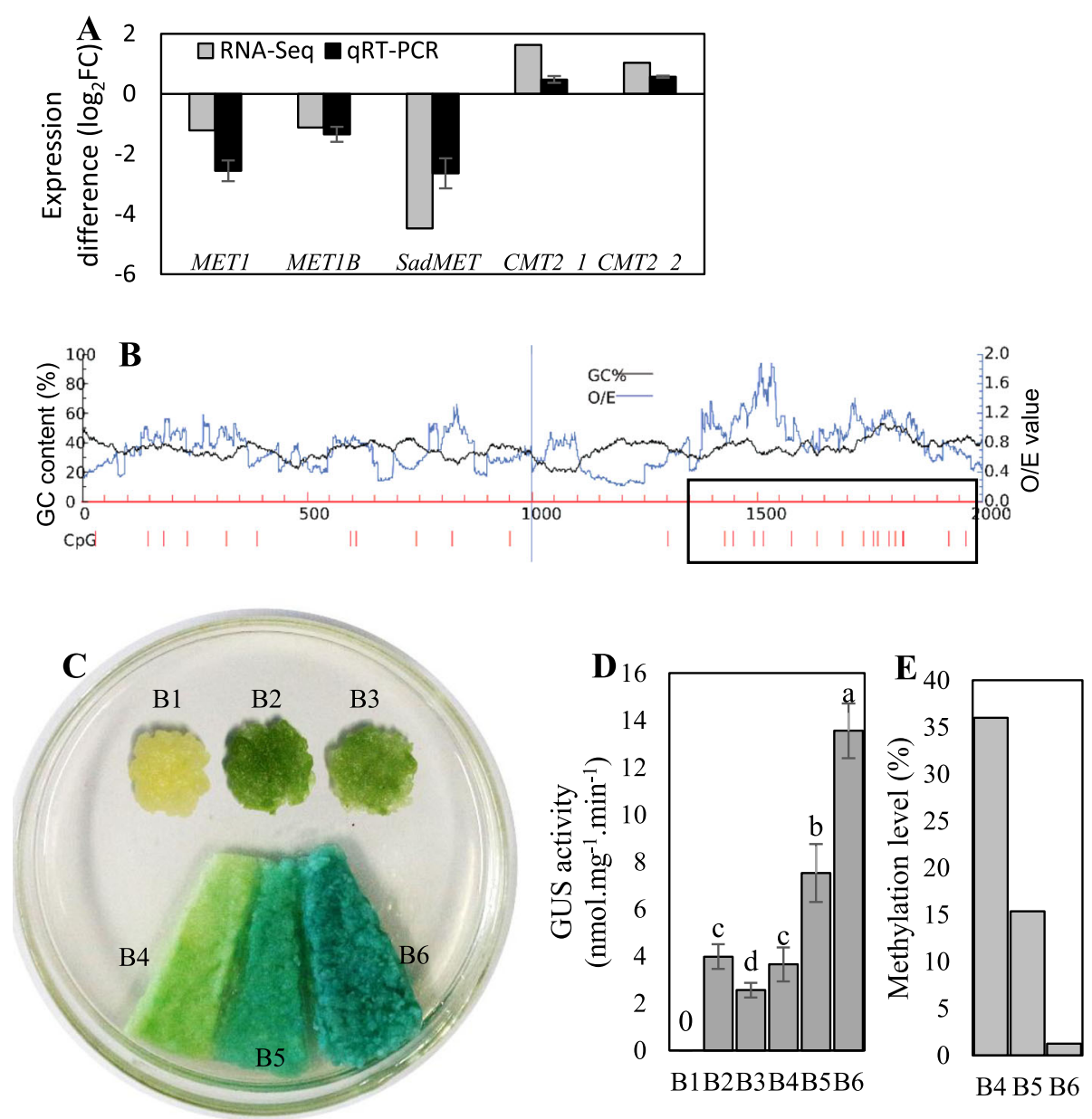

Fig. 7 Transcription capacity of the EDS1 promoter to drive GUS expression in the presence of melatonin and/or MET1. a Expression difference of the five selected genes in 'Merlot' berries at 48 HAT from RNA-Seq and qRT-PCR analyses. MET1, VIT_212s0035g01770; MET1B, VIT_212s0035g01755; SadMET, VIT_214s0006g02170; CMT2_1; VIT_216s0039g02470; CMT2_2, VIT_216s0039g02460. b Prediction of methylated cytosine in the EDS1 promoter (http://www.urogene.org/cgi-bin/methprimer2). O/E values indicate the ratio between the actual value and expected value of the CpG locus. The 800-bp region with a high CpG level indicated by the black box was used as the promoter of EDS1 ( $P_{\text {eds }}$ ) to produce the construct of $P_{\text {eds }}-35 S$ miniGUS. $c$ Histochemical analysis of the transcriptional capacity of $P_{\text {eds }}$ to drive GUS expression in grape calluses agroinfiltrated with different vector constructs: B1, control calluses; B2 and B4, Peds-35S miniGUS; B3, Peds-35S miniGUS and 35S::MET1; B5, Peds-35S miniGUS and 35S::MET1 with melatonin treatment; B6, $\mathrm{P}_{\text {eds }}-355$ miniGUS with melatonin treatment. $\mathbf{d}$ Gus activities of grape calluses infiltrated by Agrobacterium containing the B1-B6 constructs. e DNA methylation level of the EPS1 promoter, including endogenous DNA and DNA provided by $\mathrm{P}_{\text {eds }}-35 \mathrm{~S}$ miniGUS, in calluses infiltrated by Agrobacterium containing the B4-B6 constructs

driving capacity of $\mathrm{P}_{\text {eds }}$, at least partially by decreasing the methylation level of $\mathrm{P}_{\text {eds }}$.

\section{Discussion}

Methylation occurs predominantly in the CG context, followed by $\mathrm{CHG}$ and $\mathrm{CHH}$ contexts, in plants including rice (CG: 54.7\%, CHG: 37.3\%, CHH: 12\%) [25] and Arabidopsis (CG: 24\%, CHG: 6.7\%, CHH: 1.7\%) [26]. A similar pattern was observed in grape berries; however, the methylation rates in the $\mathrm{CHG}$ and $\mathrm{CHH}$ contexts in grape berries (30.35 and $27.53 \%$, respectively) were higher than those in other species such as rice and Arabidopsis, as mentioned above. Additionally, $\mathrm{CHH}$ methylation is higher in tomato fruits $(13.52-14.20 \%)$ than in leaves
(8.63\%) [27], suggesting the important role of $\mathrm{CHH}$ methylation in fruits. The gene body displayed a higher methylation level than its two flanking regions in grape berries (Fig. 2c), while contrary results have been found in citrus fruit [28]. Additionally, it is noteworthy that a global increase in DNA methylation occurs during orange fruit ripening, whereas global demethylation accompanies tomato fruit ripening $[20,27]$. Therefore, the methylation patterns of CG, CHG and CHH contexts and their biological significance vary between different species and even in different tissues of the same species, and $\mathrm{CHH}$ methylation might play an important role in fruits.

Cytosine methylation is regulated by DNA methyltransferases (MET1, CMT and DRM), demethylases 
(DME, ROS1, DML) and the chromatin-remodeling factor DDM1 [29]. In plants, the methyltransferase MET is mainly responsible for DNA methylation at the CG site [30], however MET1 also influences $\mathrm{CHH}$ methylation $[31,32]$. In this study, the significant downregulation of two MET genes (VIT_212s0035g01770 and VIT_ 212s0035g01755) might have contributed to the reduced DNA methylation observed in melatonin-treated berries (Table S3). Methylated DNAs are produced using Sadenosylmethionine as the donor of methyl groups under catalysis by SadMET [33]. The considerable downregulation of SadMET (Vit_214s0006g02170) might decrease DNA methylation levels as well (Table S3). The chromoethylase CMT mainly maintains DNA methylation at $\mathrm{CHH}$ and $\mathrm{CHG}$ sites [34]. Melatonin treatment resulted in much greater effects on $\mathrm{CHH}$ methylation than on CG and CHG methylation; therefore, $C M T$ s were expected to be downregulated by melatonin. However, only two upregulated CMT2s with very low FPKM values were detected in melatonin-treated berries (Table S3), indicating that they might not be the key enzymes responsible for the melatonin-induced decrease in $\mathrm{CHH}$ methylation. On the other hand, DNA demethylases such as DML2 are indicated to regulate DNA methylation during tomato and citrus ripening [20]. Differentially expressed DNA demethylases were not detected in the melatonin-treated berries. Taken together, the present results suggested that the melatonininduced declines in DNA methylation may be related to $M E T$ and S-adenosylmethionine-dependent methyltransferase genes and other underlying mechanisms need to be explored.

Our study showed that melatonin treatment broadly decreased genomic DNA methylation levels and modified gene expression. The correlation between DNA methylation and gene expression is very complex and is influenced by various factors, including tissue type and genomic regions [35]. Only a subset of DMRs are associated with the expression of nearby genes [36]. The role of gene body methylation in modifying gene expression is less well characterized [37]. Limited studies have shown that gene body methylation potentially plays roles in producing new functional gene transcripts by inhibiting RNA splicing [38]. The reduction in gene body methylation (Fig. 2b) and increase in RNA splicing (Table S6) suggested that melatonin increased RNA splicing by decreasing the methylation level of the gene body. In contrast, methylation in a gene promoter region prevents RNA polymerases and transcription factors from binding the promoter, thereby inhibiting DNA transcription [24]. In Arabidopsis, reduced DNA methylation contributes to the regulation of pathogen-induced gene expression in hypomethylated and hypermethylated mutants [39]. In this study, the functional annotation of
144 genes exhibiting a negative association between the levels of promoter methylation and gene expression (Table S5) suggested that melatonin might regulate gene expression by modifying promoter methylation and, hence, affect disease resistance and flavonoid biosynthesis in grape berries. This inference was also strongly supported by the similar effects of melatonin and 5-Aza on the disease resistance, total flavonoid content and changes in promoter methylation and gene expression (Fig. 6). Additionally, the promoter of EDS1 was used to verify that melatonin increased the transcription-driving capacity of the promotor by decreasing its methylation level (Fig. 7). Collectively, the results indicated that melatonin increased disease resistance and flavonoid biosynthesis at least partially by decreasing the methylation of the gene promoters involved.

Among the DMP-related genes and DEGs showing changes caused by melatonin, two PALs and STSs were interconnected in promoter methylation and gene expression (Table 1, Table S5). PAL is the first key enzyme in the phenylpropanoid pathway, in which it catalyzes the biosynthesis of cinnamic acid and provides the initial precursor for other phenolic compounds [40]. Melatonin might broadly affect phenolic metabolism by increasing $P A L$ expression. STS is responsible for the biosynthesis of resveratrol [41], and the upregulation of STSs suggests a possible role of melatonin in promoting resveratrol biosynthesis in grape berries. On the other hand, melatonin might affect disease resistance through multiple pathways based on the identified interconnected genes (Table S5). For example, EDS1 increases the robustness of the innate immune system by promoting SA biosynthesis [42]. CML41 is required for a complete defense response against bacterial pathogens by enabling $\mathrm{Ca}^{2+}$ signaling specificity, a critical component of the immune response [43]. Lectin receptor kinase is related to the activation of immune signaling involving the mitogenactivated protein kinase (MAPK) pathway [44].

\section{Conclusion}

The results indicated that melatonin led to a global decrease in the DNA methylation of grape berries, and the decrease occurred primarily at $\mathrm{CHH}$ sites, followed by CHG and CG sites. Simultaneously, melatonin broadly modified gene expression in grape berries. Melatonin increased gene expression at least partially by reducing promoter methylation and thereby promoted disease resistance and flavonoid biosynthesis.

\section{Methods}

Plant materials and experimental treatments

Grape berries were collected from 'Merlot' and 'Shine Muscat' vines that were grown at an experimental vineyard in Tai-An City, Shandong Province, China. The 
'Merlot' berries were used to determine the effects of melatonin on the DNA methylome and RNA transcriptome. Each grape cluster on a vine at 80 days after bloom was soaked for $5 \mathrm{~s}$ in a $50 \mu \mathrm{M}$ melatonin solution plus $0.05 \%(\mathrm{v} / \mathrm{v})$ Triton X-100. Control berries were treated with $0.05 \%(\mathrm{v} / \mathrm{v})$ Triton X-100. Detached 'Shine Muscat' berries were used to evaluate the effects of melatonin and a methylation inhibitor ( $5^{\prime}$-Aza) on berry disease resistance and flavonoid accumulation. The control and melatonin treatments were the same as those described above. For 5'-Aza treatment, the detached grape clusters were soaked for $5 \mathrm{~s}$ in a $20 \mu \mathrm{M} 5$-Aza solution plus $0.05 \%(\mathrm{v} / \mathrm{v})$ Triton X-100. The treated berries were placed in an environment controlled chamber (20 $\pm 1{ }^{\circ} \mathrm{C}, 80 \% \mathrm{RH}$, dark) for 21 days. 'Merlot' grape calluses were used for promoter assays. The calluses were subcultured on MS medium supplemented with $2.2 \mathrm{mg} /$ $\mathrm{L}$ thidiazuron, $10 \mathrm{mg} / \mathrm{L}$ picloram and $0.59 \mathrm{~g} / \mathrm{L} 2$ 2-(N-morpholino) ethanesulfonic acid at $25^{\circ} \mathrm{C}$ under dark conditions. The berries and calluses were collected, rinsed, frozen in liquid nitrogen, and stored at $-70{ }^{\circ} \mathrm{C}$ for the determination of DNA methylation, gene expression and other parameters.

\section{Determination of TSS, titratable acid, relative anthocyanin} contents, total flavonoids and average decay rate

Fresh berry pulp was homogenized and filtered. The filtrate was used for the determination of TSS and titratable acid. The TSS content was determined with a PAL-1 digital-display sugar meter (Atago, Tokyo, Japan). Titratable acid was measured by the titration of the filtrate with $0.1 \mathrm{M} \mathrm{NaOH}$ to $\mathrm{pH}$ 8.3. The results are expressed as mg tartaric acid per g FW. Anthocyanins were extracted and quantified, and the relative anthocyanin content was calculated as reported in our previous study [9]. The total flavonoid content was spectrophotometrically measured using rutin as the standard as described by Dewanto et al. [45]. Berry decay rate was calculated by dividing the number of decayed berries by the total number of berries. The decayed berries were visually evaluated according to the following standard: having slight mildew and moderate shrivel and brown spotting. Measurements were performed with three biological replicates. Each replicate consisted of 10 clusters (approximately 600 berries).

\section{Melatonin content determination}

Melatonin was extracted using a $\mathrm{C}_{18}$ solid-phase extraction cartridge (ProElut ${ }^{\mathrm{Tm}}$; DIKMA, China) according to our previous study [9]. Ten microliter samples were separated using a $\mathrm{BEH} \mathrm{C}_{18}$ column (Waters, $2.1 \mathrm{~mm}$ internal diameter $\times 50 \mathrm{~mm}$ length, and $1.7 \mu \mathrm{m}$ particle size) in an Acquity UHPLC system (Waters, Milford,
MA, USA). Samples were analyzed using a QTof-Micro mass spectrometer (Waters, Milford, MA, USA). The parameters and conditions of the UHPLC-MS analysis were set according to our previous study [12].

\section{Bisulfite sequencing (BS-Seq) library construction, sequencing and analysis of differentially methylated cytosines}

Genomic DNA was extracted from the control and melatonin-treated 'Merlot' grape berries. The extracted DNAs were fragmented by sonication to $200-300 \mathrm{bp}$. After end repair, the adenylation of 3 ends, and adaptor ligation, the purified ligation products of $275-350 \mathrm{bp}$ were treated with sodium bisulfite using the EZ DNA Methylation Gold Kit (Zymo Research, USA). The resultant DNAs were subjected to paired-end sequencing on the Illumina HiSeq Xten platform (Illumina, Inc., San Diego, CA, USA). Methylome sequencing and analysis were conducted by OE Biotech Co., Ltd. (Shanghai, China). Clean reads of more than $75 \mathrm{bp}$ were obtained by filtering the raw data. Cytosines in the forward strands of the clean reads and the genome were changed to thymidines, and guanines on the reverse strands were changed to adenosines in silico using Bismark software. Then, the clean reads were aligned to the grape reference genome (http:/genomes.cribi.unipd.it/DATA/ GENOME_12X/).

The detection of methylated cytosine sites and the analysis of DMRs were conducted using MethyKit software. Only the cytosine sites covered by at least 5 reads were used. The true methylated cytosine sites were confirmed by the binomial distribution of methylated and unmethylated cytosines and a false discovery rate (FDR) $\leq 0.05$. A sliding-window approach was used to screen DMRs. The methylation levels (\%) of different cytosine sites were integrated in each 1000-bp tiling window, and the integrated data for each window were used for DMR analysis. DMRs were analyzed using the logistic regression mode and identified on the basis of changes in methylation levels (fold change $\geq 4$ or $\leq 0.25$ ) and an $\mathrm{FDR} \leq 0.05$. Additionally, the region $2000 \mathrm{bp}$ upstream of a transcription start site was taken as the promoter region for the analysis of differentially methylated promoters (DMPs). For DMP analysis, the sliding window was set to $2000 \mathrm{bp}$, and the other analysis methods were the same as those for DMR analysis. Three biological replicates were performed for the control and melatonin treatment.

RNA library construction, sequencing and DEG analysis RNA library construction was performed using the TruSeq Stranded mRNA LT Sample Prep Kit (Illumina, San Diego, CA, USA) according to the manufacturer's instructions. The RNA libraries were sequenced using the 
Illumina HiSeq Xten platform (Illumina, Inc., San Diego, CA, USA), and 150-bp paired-end reads were generated. The clean reads were mapped to the grape genome (http://genomes.cribi.unipd.it/DATA/GENOME_12X/) using HISAT2. Unigene expression levels were quantified according to FPKM values, which were calculated using Cufflinks. DEGs between two samples were screened using an absolute $\log _{2}$ (fold change) $\geq 1$ and an FDR $\leq 0.05$ as the thresholds. Three biological replicates were generated for the control and melatonin-treated berries.

\section{Bisulfite-RT-PCR (BS-PCR) and quantitative RT-PCR (qRT- PCR)}

BS-PCR analysis of three genes was performed to validate the quality of BS sequencing. The DNAs extracted from the control and melatonin-treated berries were treated with bisulfate using an EZ DNA Methylation Gold Kit (Zymo Research, USA). The promoter regions of the above three genes were amplified using specific primers designed with Methyl Primer Express v2.0 (http://www.urogene.org/cgi-bin/methprimer2; Table S7). The BS-PCR products were cloned into pMD19-T (TaKaRa, Dalian, China), and 30 positive clones were sequenced. The sequencing results were used to calculate methylation levels with the online software BiQ Analyzer (http://biq-analyzer.bioinf.mpi-inf.mpg.de/). $\quad$ qRT-PCR was performed using SYBR Green Master-Mix (SYBR Premix EX Taq TM, Dalian, China) on a Bio-Rad iQ5 (Hercules, CA, United States) instrument, and the primers are listed in Table S7.

\section{Transient transformation of the EDS1 promoter and MET1 into grape calluses}

The promoter sequence of EDS1, $800 \mathrm{bp}$ upstream of ATG, was cloned (see the specific primers in Table S7) and fused upstream of the $35 \mathrm{~S}$ minimal promoter of pRI101-GUS (Takara, Dalian, China) to generate the $\mathrm{P}_{\text {eds }}: 35 \mathrm{~S}$ miniGUS plasmid. The ORF of MET1 was cloned (see the specific primers in Table S7) and fused downstream of the $35 \mathrm{~S}$ sequence of pRI101 to generate the 35S::MET1 plasmid. The above two plasmids were introduced into Agrobacterium strain GV3101. The Agrobacterium-mediated transient transformation of grape calluses was performed according to a previous study [5]. Grape calluses were immersed in an Agrobacterium suspension and gently shaken for 20 min. After blotting dry on sterile filter paper, the calluses were transferred to solid MS medium containing $100 \mu \mathrm{M}$ acetosyringone. After 3 days of coculture in darkness at $28^{\circ} \mathrm{C}$, the calluses were collected and subjected to GUS staining and activity assays. GUS histochemical staining and activity assays were conducted according to a previously reported method as described by Jefferson et al.
[46]. GUS activity was expressed as nmol of 4methylumbelliferone per mg protein per minute.

Inoculation of single detached berries with $B$. cinerea.

The detached 'Merlot' berries were soaked for $5 \mathrm{~s}$ in a $50 \mu \mathrm{M}$ melatonin or $20 \mu \mathrm{M} 5$ ' -Aza solution plus $0.05 \%$ $(\mathrm{v} / \mathrm{v})$ Triton $\mathrm{X}-100$. The berries were then gently wounded with a razor blade to break the surface of the berries. Wounded berries were inoculated by spraying with a suspension of $B$. cinerea $\left(1 \times 10^{4}\right.$ conidia/ml). After inoculation, berries were placed in an environment controlled chamber $\left(20 \pm 1^{\circ} \mathrm{C}, 90 \% \mathrm{RH}\right.$, dark).

\section{Statistical analyses}

Statistical analysis was performed using SPSS (v19.0) software. One-way analysis of variance followed by Duncan's multiple range test was employed.

\section{Supplementary information}

Supplementary information accompanies this paper at https://doi.org/10. 1186/s12870-020-02445-w.

Additional file $\mathbf{1}$ Table $\mathbf{S 1}$ Details of the bisulfite sequencing, mapping and identification of methylated cytosines (mCs).

Additional file $\mathbf{2}$ Table $\mathbf{S 2}$ Differentially methylated regions (DMR, fold change $\geq 4$ or $\leq 0.25, P<0.05$ ) and DMR-related genes.

Additional file 3 Table S3 Differentially expressed genes (DEGs) between the control and melatonin-treated berries $\left(\left|\log _{2} F C\right|>1, P<0.05\right)$.

Additional file $\mathbf{4}$ Table $\mathbf{S 4}$ Cross-analysis of DMR-related genes and DEGs.

Additional file $\mathbf{5}$ Table S5 Cross-analysis of DMP-related genes and DEGs.

Additional file $\mathbf{6}$ Table S6 Alternative splicing frequency statistics for the control and melatonin-treated berries.

Additional file $\mathbf{7}$ Table $\mathbf{5 7}$ Primers used in this study.

\section{Abbreviations}

DAB: Days after bloom; DAT: Days after treatment; DEG: Differentially expressed genes; DMP: Differentially methylated promoter;

DMR: Differentially methylated region; EDS1: Enhanced disease susceptibility 1; FC: Fold change; 5-Aza: 5-azacytidine; GO: Gene ontology; mC: methylated cytosine; HAT: Hours after treatment; MET1: DNA (cytosine-5)methyltransferase 1; SadMET: S-adenosylmethionine-dependent methyltransferase; TSS: Total soluble solids

\section{Acknowledgments}

Not applicable.

\section{Authors' contributions}

$Y Y$ and SG conceived and designed the research; SG, WM and $X L$ performed the experiments; SG and XC analyzed the data; and YY wrote the manuscript. All authors read and approved the manuscript.

\section{Funding}

This study was financially supported by National Key R\&D Program of China (2018YFD1000200), the Key Research and Development Program of Shandong Province (2019GNC106149), the National Natural Science Foundation of China (31872068), and the Funds of Shandong "Double Tops" Program (SYL2017YSTD10). None of the funding bodies have any role in the design of the study or collection, analysis, and interpretation of data as well as in writing the manuscript. 


\section{Availability of data and materials}

Full BS-Seq and RNA-Seq data were submitted to the sequence read archive (SRA) of NCBI under BioSample accessions PRJNA603630 and PRJNA603632, respectively (https://www.ncbi.nlm.nih.gov/sra).

\section{Ethics approval and consent to participate}

Not applicable.

\section{Consent for publication}

Not applicable.

\section{Competing interests}

The authors declare that they have no competing interests.

Received: 4 February 2020 Accepted: 14 May 2020

Published online: 24 May 2020

\section{References}

1. Murch SJ, Hall BA, Le CH, Saxena PK. Changes in the levels of indoleamine phytochemicals during veraison and ripening of wine grapes. J Pineal Res. 2010;49:95-100.

2. Shi H, Chen Y, Tan DX, Reiter RJ, Chan Z, He C. Melatonin induces nitric oxide and the potential mechanisms relate to innate immunity against bacterial pathogen infection in Arabidopsis. J Pineal Res. 2015;59:102-8.

3. Liu CX, Chen LL, Zhao RR, Li R, Zhang SJ, Yu WQ, et al. Melatonin induces disease resistance to Botrytis cinereal in tomato fruit by activating jasmonic acid signaling pathway. J Agric Food Chem. 2019;67:6116-24.

4. Wei YX, Chang YL, Zeng HQ, Liu GY, He CZ, Shi HT. RAV transcription factor are essential for disease resistance against assava bacterial blight via activation of melatonin biosynthesis genes. J Pineal Res. 2018;64(1):e1245.

5. Xu LL, Xiang GQ, Sun QH, Ni Y, Jin ZX, Gao SW, et al. Melatonin enhances salt tolerance by promoting MYB108A-mediated ethylene biosynthesis in grapevines. Hortic Rese. 2019;6:114.

6. Li C, Tan DX, Liang D, Chang C, Jia D, Ma F. Melatonin mediates the regulation of $A B A$ metabolism, free-radical scavenging, and stomatal behaviour in two Malus species under drought stress. J Exp Bot. 2014;66: $669-80$

7. Zuo B, Zheng X, He P, Wang L, Lei Q, Feng C, et al. Overexpression of MzASMT improves melatonin production and enhances drought tolerance in transgenic Arabidopsis thaliana plants. J Pineal Res. 2014;57:408-17.

8. Fan JB, Xie Y, Zhang ZC, Chen L. Melatonin: a multifunctional factor in plants. Int J Mol Sci. 2018;19:1528.

9. Xu LL, Yue QY, Xiang GQ, Bian FE, Yao YX. Melatonin promotes ripening of grape berry via increasing the levels of $\mathrm{ABA}, \mathrm{H} 2 \mathrm{O} 2$ and particularly ethylene. Horti Res. 2018;5:41.

10. Sun QQ, Zhang N, Wang JF, Li DB, Shi J, Li R, et al. Melatonin promotes ripening and improves quality of tomato fruit during postharvest life. J Exp Bot. 2015;66:657-68

11. Hu W, Yang H, Tie WW, Yan Y, Ding ZH, Liu Y, et al. Natural variation in banana varieties highlights the role of melatonin in postharvest ripening and quality. J Agric Food Chem. 2017;65:9987-94.

12. Xu LL, Yue QY, Bian FE, Sun H, Zhai H, Yao YX, et al. Front Plant Sci. 2017;8: 1426.

13. Meng JF, Yu Y, Shi TC, Fu YS, Zhao T, Zhang ZW. Melatonin treatment of pre-veraison grape berries modifies phenolic components and antioxidant activity of grapes and wine. Food Sci Technol Campinas. 2019;39(1):35-42.

14. Liang CZ, Zheng GY, Li WZ, Wang YQ, Hu B, Wang HR, et al. Melatonin delays leaf senescence and enhances salt stress tolerance in rice. J Pineal Res. 2015;59:91-101.

15. Sun QQ, Zhang N, Wang JF, Cao YY, Li XS, Zhang HJ, et al. A label-free differential proteomics analysis reveals the effect of melatonin in promoting fruit ripening and anthocyanin accumulation upon post-harvest in tomatoes. J Pineal Res. 2016;61(2):138-53.

16. Arnao MB, Hernández-Ruiz J. Melatonin: a new plant hormone and/or a plant master regulator. Trends Plant Sci. 2019;24(1):38-48.

17. Grafi G. Epigenetics in plant development and response to stress. BBA-Gene Regul Mech. 2011;1809:351-2.

18. Giovannoni J, Nguyen C, Ampofo B, Zhong S, Fei Z. The epigenome and transcriptional dynamics of fruit ripening. Annu Rev Plant Biol. 2017;68(1): $61-84$.
19. Feng SJ, Liu XS, Tao H, Tan SK, Chu SS, Oono Y, et al. Variation of DNA methylation patterns associated with gene expression in rice (Oryza sativa) exposed to cadmium. Plant Cell Environ. 2016;39(12):2629-49.

20. Huang H, Liu RE, Niu QF, Tang K, Zhang B, Zhang H, et al. Global increase in DNA methylation during orange fruit development and ripening. PNAS. 2019:116(4):1430-6.

21. Liu R, How-Kit A, Stammitti L, Teyssier E, Rolin D, Mortain-Bertrand A, et al. A EMETER-like DNA demethylase governs tomato fruit ripening. PNAS. 2015; 112(34):10804-9.

22. Lee SE, Kim SJ, Yoon HJ, Yu SY, Yang HN, Jeong S, et al. Genome-wide profiling in melatonin-exposed human breast cancer cell lines identifies differentially methylated genes involved in the anticancer effect of melatonin. J Pineal Res. 2013:54(1):80-8.

23. Martin V, Sanchez-Sanchez AM, Herrera F, Gomez-Manzano C, Fueyo J, Alvarez-Vega, et al. Melatonin-induced methylation of the ABCG2/BCRP promoter as a novel mechanism to overcome multidrug resistance in brain tumour stem cells. Brit J Cancer. 2013:108:2005-12.

24. Maurano MT, Wang H, John S, Shafer A, Canfield T, Lee K, et al. Role of DNA methylation in modulating transcription factor occupancy. Cell Rep. 2015;12: 1184-95.

25. Li X, Zhu JD, Hu FY, Ge S, Ye MZ, Xiang H, et al. Single-base resolution maps of cultivated and wild rice methylomes and regulatory roles of DNA methylation in plant gene expression. BMC Genomics. 2012;13:300.

26. Cokus SJ, Feng SH, Zhang XY, Chen ZG, Merriman B, Haudenschild CD, et al. Shotgun bisulphite sequencing of the Arabidopsis genome reveals DNA methylation patterning. Nature. 2008;452:215-9.

27. Zhong SL, Fei Z, Chen YR, Zheng Y, Huang MY, Vrebalov J, et al. Single-base resolution methylomes of tomato fruit development reveal epigenome modifications associated with ripening. Nat Biotech. 2013;31(2):154-61.

28. Xu JD, Wang X, Cao HB, Xu HD, Xu Q, Deng XX. Dynamic changes in methylome and transcriptome patterns in response to methyltransferase inhibitor 5-azacytidine treatment in citrus. DNA Res. 2017:24(5):509-22.

29. Chan SW, Henderson IR, Jacobsen SE. Gardening the genome: DNA methylation in Arabidopsis thaliana. Nat Rev Genet. 2005:6:351-60.

30. Kim M, Ohr H, Lee JW, Hyun YB, Fischer RL, Choi Y. Temporal and spatial downregulation of Arabidopsis MET1 activity results in global DNA hypomethylation and developmental defects. Mol Cells. 2008;26(6):611-5.

31. Graindorge $S$, Cognat V, Johann to Berens $P$, Mutterer J, Molinier J. Photodamage repair pathways contribute to the accurate maintenance of the DNA methylome landscape upon UV exposure. PLoS Genet. 2019;15(11): e1008476.

32. Stroud $H$, Greenberg MV, Feng S, Bernatavichute $Y$, Jacobsen SE. Comprehensive analysis of silencing mutants reveals complex regulation of the Arabidopsis methylome. Cell. 2013;1-2:352-64.

33. Jeltsch A. Beyond Watson and Crick: DNA methylation and molecular enzymology of DNA methyltransferases. Chembiochem. 2002;3:274-93.

34. Noy-Malka C, Yaari R, Itzhaki R, Mosquna A, Gershovitz NA, Katz A, et al. A single CMT methyltransferase homolog is involved in CHG DNA methylation and development of Physcomitrella patens. Plant Mol Biol. 2014;84(6):719-35

35. Wang J, Marowsky NC, Fan CZ. Divergence of gene body DNA methylation and evolution of plant duplicate genes. PLoS One. 2014;9:e110357.

36. Eichten SR, Briskine R, Song J, Li Q, Swanson-Wagner R, Hermanson PJ, et al. Epigenetic and genetic influences on DNA methylation variation in maize populations. Plant Cell. 2013:25:2783-97.

37. Tirnaz S, Batley J. DNA methylation: toward crop disease resistance improvement. Trends Plant Sci. 2019:24(12):1137-50.

38. Regulski M, Lu ZY, Kendall J, Donoghue MTA, Reinders J, Llaca V, et al. The maize methylome influences mRNA splice sites and reveals widespread paramutation-like switches guided by small RNA. Genome Res. 2013;23: 1651-62.

39. Sánchez AL, Stassen JHM, Furci L, Smith LM, Ton J. The role of DNA (de) methylation in immune responsiveness of Arabidopsis. Plant J. 2016:88:361-74

40. Huang JL, Gu M, Lai ZB, Fan BF, Shi K, Zhou YH, et al. Functional analysis of the Arabidopsis PAL gene family in plant growth, development, and response to environmental stress. Plant Physiol. 2010;153(4):1526-38.

41. Shi JL, He MY, Cao JL, Wang H, Ding JH, Jiao YT, et al. The comparative analysis of the potential relationship between resveratrol and stilbene synthase gene family in the development stages of grapes (Vitis quinquangularis and Vitis vinifera). Plant Physiol Biochem. 2014;74:24-32. 
42. Cui HT, Gobbato E, Kracher B, Qiu JD, Bautor J, Parker JE. A core function of EDS1 with pad4 is to protect the salicylic acid defense sector in Arabidopsis immunity. New Phytol. 2017;213:1802-17.

43. Xu B, Cheval C, Laohavisit A, Hocking B, Chiasson D, Olsson TSG, et al. A calmodulin-like protein regulates plasmodesmal closure during bacterial immune responses. New Phytol. 2017;215:77-84.

44. Park J, Kim TH, Takahashi Y, Schwab R, Dressano K, Stephan AB, et al. Chemical genetic identification of a lectin receptor kinase that transduces immune responses and interferes with abscisic acid signaling. Plant J. 2019; 98(3):492-510.

45. Dewanto V, Wu X, Adom KK, Liu RH. Thermal processing enhances the nutritional values of tomatoes by increasing the total antioxidant activity. J Agric Food Chem. 2002;50:3010-4.

46. Jefferson RA, Kavanagh TA, Bevan MW. GUS fusions, beta-glucuronidase as a sensitive and versatile gene fusion marker in higher plants. EMBO J. 1987;6:3901-7.

\section{Publisher's Note}

Springer Nature remains neutral with regard to jurisdictional claims in published maps and institutional affiliations.

Ready to submit your research? Choose BMC and benefit from:

- fast, convenient online submission

- thorough peer review by experienced researchers in your field

- rapid publication on acceptance

- support for research data, including large and complex data types

- gold Open Access which fosters wider collaboration and increased citations

- maximum visibility for your research: over $100 \mathrm{M}$ website views per year

At $\mathrm{BMC}$, research is always in progress.

Learn more biomedcentral.com/submissions 